\title{
Deriving tree growth models from stand models based on the self- thinning rule of Chinese fir plantations
}

\author{
Xiongqing Zhang ${ }^{(1-2)}$, \\ Quang V Cao ${ }^{(3)}$, \\ Yancheng $Q u^{(1)}$, \\ Jianguo Zhang ${ }^{(1)}$
}

\begin{abstract}
Self-thinning due to density-dependent mortality usually occurs during the forest development. To improve predictions of such processes during forest successions under climate change, reliable stand-level models are needed. In this study, we developed an integrated system of tree- and stand-level models by deriving tree diameter and survival models from stand growth and survival models based on climate-sensitive self-thinning rule of Chinese fir plantations in subtropical China. The resulting integrated system, having a unified mathematical structure, should provide consistent estimates at both tree and stand levels. Predictions were reasonable at both stand and tree levels. Because stand-level values aggregated from the tree model outputs are different from those predicted directly from the stand models, the disaggregation approach was applied to provide numerical consistency between models of different resolutions. Compared to the unadjusted approach, predictions from the disaggregation approach were slightly worse for tree survival but slightly better for tree diameter. Because the stand models were developed under the climatesensitive self-thinning trajectory, the integrated system could offer reasonable predictions that could aid in managing Chinese fir plantations under climate change.
\end{abstract}

Keywords: Chinese Fir, Self-thinning Rule, Disaggregation, Stand Model, Tree Model tree species (Charru et al. 2012), initial spacing (VanderSchaaf \& Burkhart 2012), site quality (Bi 2001), and climate conditions (Zhang et al. 2018).

Because the self-thinning rule refers to density-dependent mortality, it has been used as the basis for developing stand management diagrams (VanderSchaaf \& Burkhart 2012, Stankova \& Diéguez-Aranda 2020), constructing density indices (Woodall et al. 2005), and especially for predicting forest growth and stand survival (Monserud et al. 2004). Note that in this study, stand survival is defined as number of surviving trees per ha.

Forest growth and yield models provide an important basis for managing forest reasonably. These models are categorized
(1) Key Laboratory of Tree Breeding and Cultivation of the National Forestry and Grassland Administration, Research Institute of Forestry, Chinese Academy of Forestry, Beijing 100091 (P. R. China); (2) Collaborative Innovation Center of Sustainable Forestry in Southern China, Nanjing Forestry University, Nanjing, 210037 (P. R. China); (3) School of Renewable Natural Resources, Louisiana State University (USA)

@ Jianguo Zhang (xqzhang85@yahoo.com)

Received: Feb 24, 2021 - Accepted: Nov 17, 2021

Citation: Zhang X, Cao QV, Qu Y, Zhang J (2022). Deriving tree growth models from stand modelsbased on the self-thinning rule of Chinese fir plantations. iForest 15: 1-7. - doi: 10.3832/ifor3792-014 [online 2022-01-13]

Communicated by: Alessio Collalti into four kinds of models: whole-stand models, size-class models, diameter distribution models, and individual tree-models (Burkhart \& Tomé 2012). Whole-stand models offer information on the whole stand such as stand basal area (Lam \& Guan 2020), stand survival (Scolforo et al. 2019), and stand volume (Huuskonen \& Miina 2007). Size-class models deal with trees classified into diameter classes. These models include stand-table projection models, which predict the frequency in each diameter class (Nepal \& Somers 1992, Allen et al. 2011), and diameter-distribution models, which use a probability density function to model the diameter distributions (Carretero \& Alvarez 2013). Individual-tree models, on the other hand, provide detailed tree information such as tree diameter growth (Subedi \& Sharma 2011), tree survival (Monserud \& Sterba 1999), or both (Mabvurira \& Miina 2002). stand models provide more accurate standlevel predictions than individual-tree models, because stand-level predictions aggregated from tree models usually lead to accumulating errors in plantations ( $Q$ in \& Cao 2006). For the same site, a forest manager might prefer stand-level models to predict stand attributes, but might need tree models to aid management decisions that require detailed tree-level information. Because stand-level attributes predicted from tree and stand-level models are numerically inconsistent with each other, disaggrega-
In general, for unthinned stands whole- 
Tab. 1 - Mean annual temperature (MAT), annual precipitation (AP), degree-days below $0^{\circ} \mathrm{C}(\mathrm{DDO})$, summer mean maximum temperature (SMMT), and winter mean minimum temperature (WMMT) of study period, by site.

\begin{tabular}{lccccc}
\hline Site & MAT $\left({ }^{\circ} \mathrm{C}\right)$ & AP $(\mathrm{mm})$ & DD0 & SMMT $\left({ }^{\circ} \mathrm{C}\right)$ & WMMT $\left({ }^{\circ} \mathrm{C}\right)$ \\
\hline Fujian & 18.90 & 1768 & 1 & 32.18 & 4.75 \\
\hline Jiangxi & 18.04 & 1572 & 2 & 32.01 & 4.23 \\
\hline Guangxi & 22.27 & 1494 & 0 & 31.79 & 12.24 \\
\hline Sichuan & 18.31 & 1179 & 1 & 30.69 & 7.09 \\
\hline
\end{tabular}

tion has been employed as a method for maintaining compatibility between the two types of models (Ritchie \& Hann 1997). This method attempts to adjust stand-level variable predictions obtained from individualtree models such that the aggregated predictions would match the outputs of whole-stand model (Ritchie \& Hann 1997).

Chinese fir (Cunninghamia lanceolate (Lamb.) Hook.) is a native coniferous tree species widespread in southern China. It is commonly used for timber production be cause its straight stem and good resistance to bending and cracking (Zhang et al. 2020). The planting area for this species is about 8.95 million hectares, about 30\% of all afforestation in China (Lei 2005). Zhang et al. (2016) used the segmented regression technique to develop the self-thinning model of Chinese fir plantations. The slopes in the self-thinning lines were found to be variable from site to site, and could be predicted by the use of several climate factors (Zhang et al. 2018). Based on this work, Zhang et al. (2020) developed a system of stand basal area, quadratic mean diameter growth, and survival models ac cording to the self-thinning rule. They found that the stand models under the climate-sensitive self-thinning trajectories provided reasonable predictions under climate change.

Daniels \& Burkhart (1988) put forward a

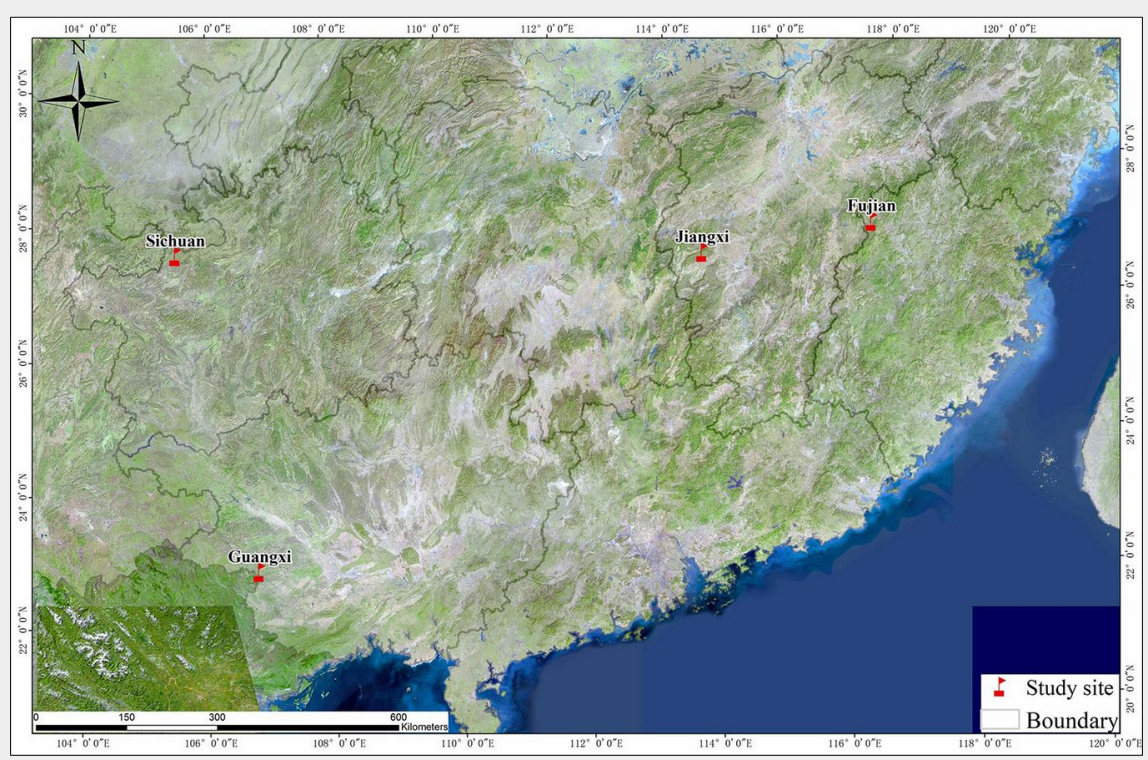

Fig. 1 - Study sites located in subtropical climate zones in this study.

\section{Materials and methods}

\section{Study sites and data measurement}

The experimental sites were situated in Fujian, Jiangxi, Guangxi, and Sichuan provinces in southern China. Fujian, Jiangxi, and Sichuan provinces belong to middle-subtropical climate zones, whereas Guangxi has southern-subtropical climate (Tab. 1 and Fig. 1). The landforms at the four sites are low mountains and high hills, with elevation ranging from 300 to $500 \mathrm{~m}$ a.s.l. Parent rocks in Fujian and Guangxi are Granite. In Jiangxi and Sichuan, parent rocks are sandy shale and shale, respectively. The soil type is mainly Laterite for Fujian, Guangxi, and Sichuan, and is mainly yellowbrown for Jiangxi.

The plots were planted in 1982 in Fujian, Guangxi and Sichuan, and in the spring of 1981 in Jiangxi. Each site was established with four planting densities: $2 \times 1.5 \mathrm{~m}(3333$

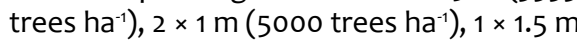
(6667 trees ha $\left.{ }^{-1}\right)$, and $1 \times 1 \mathrm{~m}$ (10,000 trees $\left.\mathrm{ha}^{-1}\right)$. The experiments were installed in a random block arrangement with three replications for each level. Four plots were distributed in each block (one plot for each spacing trial). In each site, twelve plots (20 $\times 30 \mathrm{~m}$ each) were established. Surrounding each plot there were two rows of trees with the same spacing, which formed a buffer zone.

In each plot, diameters at a height of 1.3 $\mathrm{m}(\mathrm{dbh})$ of all trees were measured, and over 50 trees were randomly chosen for measuring height. Dominant height was computed as the average height of the six tallest trees in the sample. In 1998, a snowstorm in Jiangxi killed some trees, and therefore the data after 1999 for this site were dropped from this study. The study period ranged from 1985 to 2010 in Fujian, 1985 to 1999 in Jiangxi, 1990 to 2009 in Guangxi, and 1985 to 2013 in Sichuan. Field measurement was done in the winter every 1 to 3 years. Tab. 2 showed the summary statistics of stand and tree factors by replication. Fig. 2 showed the number of trees per ha over time.

\section{Height-age model}

The stand-level models (described further below) require projection of dominant height over time. The height-age model developed by Bailey \& Clutter (1974) has been found to perform well in modeling the dominant height growth of Chinese fir (eqn. 1):

$$
\hat{H}_{i, t+p}=\operatorname{Exp}\left\{\beta_{1}+\left[\ln \left(H_{i t}\right)-\beta_{1}\right]\left(\frac{A_{i, t+p}}{A_{i, t}}\right)^{\beta_{2}}\right\}
$$

where $H_{\text {it }}$ is the dominant height (m) of plot $i$ at year $t, A_{i t}$ is the stand age (years) of plot $i$ at year $t, p$ is the growth period in years, the ${ }^{\wedge}$ denotes predicted values, and $\beta_{1}-\beta_{2}$ are parameters to be estimated, with values listed in Zhang et al. (2020).

\section{Stand-level growth and survival models} Zhang et al. (2020) developed a system to 
predict stand quadratic mean diameter growth and survival. The quadratic mean diameter was predicted as follows (eqn. 2):

$$
\begin{aligned}
& \hat{Q}_{i, t+1}=\operatorname{Exp}\left\{\left(A_{i t} / A_{i, t+1}\right) \ln \left(Q_{i t}\right)\right. \\
& \quad+\left(1-A_{i t} / A_{i, t+1}\right) \\
& \left.\quad\left[\chi_{0}+\chi_{1} A_{i t}+\chi_{2} H_{i t}+\chi_{3} Q_{i t}+\chi_{4} \ln \left(N_{i t}\right)\right]\right\}
\end{aligned}
$$

where $Q_{\text {it }}$ is the stand quadratic mean diameter $(\mathrm{cm})$ of plot $i$ at year $t, N_{i t}$ is the number of trees per ha of plot $i$ at year $t$, and $\chi_{0}-\chi_{4}$ are parameters to be estimated.

Prediction of stand survival was based on the climate-sensitive self-thinning model (Zhang et al. 2018 - eqn. 3-5):

$$
\begin{aligned}
& \hat{y}_{i, t+1}=y_{i t} \\
& +\alpha_{3}\left\{\begin{array}{l}
\left(w_{i, t+1}\right)^{2} I_{12}-\left(w_{i, t+1}-\frac{c_{i}}{2 \alpha_{3}}\right)^{2} I_{22} \\
-\left(w_{i t}\right)^{2} I_{11}-\left(w_{i t}-\frac{c_{i}}{2 \alpha_{3}}\right)^{2} I_{21}
\end{array}\right\} \\
& w_{i, t+1}=x_{i, t+1}-\alpha_{1}-\alpha_{2} y_{i 0} \\
& w_{i t}=x_{i t}-\alpha_{1}-\alpha_{2} y_{i 0}
\end{aligned}
$$

where $d_{i, t,}$ is the tree diameter $(\mathrm{cm})$ at $1.3 \mathrm{~m}$ height of tree $j$ in plot $i$ at year $t$, and $\chi_{5}$ is a tree-level parameter to be estimated (see further below). based on stand survival prediction. The tree survival probability, expressed as a

(4) function of current quadratic mean diame-

ter and current and future number of trees

where $y_{i t}=\ln \left(N_{i t}\right), x_{i t}=\ln \left(Q_{i t}\right), y_{i 0}=\ln \left(N_{i 0}\right), N_{\text {io }}$ $=$ planting density (number of trees ha-1) for plot $i$, and (eqn. 6-7):

$I_{11}= \begin{cases}1 & \text { if } x_{i t}>\alpha_{i}+\alpha_{2} y_{i 0} \\ 0 & \text { otherwise }\end{cases}$

$I_{22}= \begin{cases}1 & \text { if } x_{i t}>\alpha_{i}+\alpha_{2} y_{i 0}+\frac{c_{i}}{2 \alpha_{3}} \\ 0 & \text { otherwise }\end{cases}$

with $c_{i}$ being the self-thinning slope for plot $i$, given by (eqn. 8):

$$
\begin{aligned}
c_{i} & =c_{0}+c_{1} M A T_{i}+c_{2} A P_{i} \\
& +c_{3} D D 0_{i}+c_{4} S M M T_{i}+c_{5} W M M T
\end{aligned}
$$

where $c_{0}-C_{5}$ are regression parameters, with values listed in Zhang et al. (2018), MAT is the mean annual temperature, $A P$ is the annual precipitation, DDo are the degree-days below $0{ }^{\circ} \mathrm{C}$, SMMT is the mean maximum temperature of months in summer, WMMT is the mean minimum temperature of winter months, and $\alpha_{1}-\alpha_{3}$ are the parameters to be estimated.

Stand basal area is computed using stand quadratic mean diameter and survival (eqn. 9):

$$
\hat{B}_{i, t+1}=K \hat{N}_{i, t+1} \hat{Q}_{i, t+1}^{2}
$$

where $\hat{B}_{\mathrm{i}, \mathrm{t}+1}$ is the stand basal area prediction $\left(m^{2} h^{-1}\right)$ of plot $i$ at year $t+1$, and $K=\pi /$ 40000.

\section{Tree-level growth and survival models}

Given the above stand-level models, individual tree models can be derived from their outputs. Tree diameter was obtained from the predicted quadratic mean diameter as follows (eqn. 10):

$$
\hat{d}_{i j, t+1}=\hat{Q}_{i, t+1}\left(\frac{d_{i j, t}}{Q_{i, t}}\right)^{\chi_{s}}
$$

Cao (2019) derived a tree survival model

Tab. 2 - Summary statistics (mean \pm standard deviation) of stand- and tree-level variables of Chinese fir plantations from 1985 to 2013, by replication.

\begin{tabular}{lccc}
\hline Variable & Replication 1 & Replication 2 & Replication 3 \\
\hline A: stand age (years) & $13 \pm 6.2$ & $12 \pm 6.0$ & $12 \pm 6.0$ \\
\hline N: number of trees ha $^{-1}$ & $6159 \pm 2473$ & $6120 \pm 2495$ & $6080 \pm 2452$ \\
\hline B: stand basal area $\left(\mathrm{m}^{2} \mathrm{ha}^{-1}\right)$ & $36.12 \pm 16.32$ & $33.89 \pm 16.81$ & $36.94 \pm 15.34$ \\
\hline Q: quadratic mean diameter $(\mathrm{cm})$ & $9.0 \pm 3.0$ & $8.7 \pm 3.2$ & $9.2 \pm 3.2$ \\
\hline H: stand dominant height $(\mathrm{m})$ & $11.1 \pm 3.9$ & $11.2 \pm 4.5$ & $11.4 \pm 4.1$ \\
\hline d: tree diameter at breast height $(\mathrm{cm})$ & $8.7 \pm 3.8$ & $8.4 \pm 3.9$ & $8.9 \pm 4.0$ \\
\hline
\end{tabular}

per ha, is listed below in annual form (eqn. 11):

$$
P_{i j, t+1}=\frac{1}{1+\left(\frac{N_{i, t}-\hat{N}_{i, t+1}}{\hat{N}_{i, t+1}}\right) \exp \left[\delta_{1}\left(d_{i j, t}-\delta_{2} Q_{i, t}\right)^{\delta_{3}}\right]}
$$

where $P_{i, t+1}$ is the tree survival probability prediction of tree $j$ nested in plot $i$ at year $t+1$, and $\delta_{1}-\delta_{3}$ are parameters to be estimated. Eqn. 7 and eqn. 8 form the treelevel models, with parameters $\chi_{5}, \delta_{1}, \delta_{2}$, and $\delta_{3}$ to be estimated from the tree data.

Because of different growth intervals, the annual growth projection method was used to model the survival and growth models to ensure the step-invariance property of the predictions. Stand-level models were predicted annually in a recursive way: quadratic mean diameter and stand survival were projected repeatedly from equations for $Q$ and $y$ from age $t_{1}$ to $t_{2}$, from $t_{2}$ to
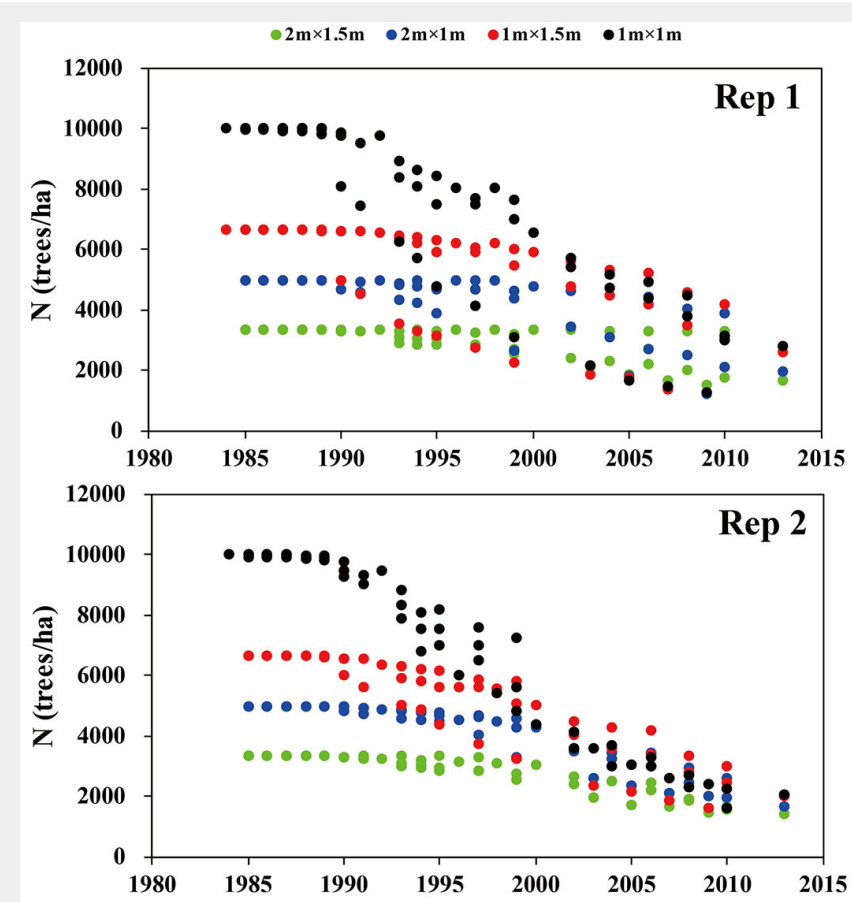

Fig. 2 - Number of trees per ha $(\mathrm{N})$ over time by replication. Fujian: every year from 1985 to 1990 ; every two years from 1990 to 2010; Jiangxi: every year from 1985 to 1989 ; every two years from 1989 to 1999 ; Guangxi: every year from 1990 to 1995; every two years from age 1995 to 2009; Sichuan: every year from 1985 to 1995; every two years from 1995 to 1999 and from 2002 to 2010; every three years from 1999 to 2002 and 2010 to 2013. 
$t_{3}$, and so on until the end of the growing period. The tree-level models can be derived either at each intermediate age or at the end of the growth period.

\section{Parameter estimation}

The Sequential Estimation approach (Cao 2017) was employed in this study. This approach involves estimating parameters sequentially, with some parameters estimated at the stand level and the remaining parameters at the tree level. At the standlevel phase, parameters in equations for $Q$, $y$, and $B$ were estimated via the Seemingly Unrelated Regression (SUR) method using the procedure MODEL in SAS (SAS Institute 2011). At the tree-level phase, parameters in equations for $p$ and $d$ were estimated using the maximum likelihood approach.

\section{Disaggregation}

Outputs from the stand-level models were often different in values from stand outputs aggregated from tree-level models. The following disaggregation method (Cao 2017) was used for adjusting tree survival and diameter predictions. The advantage of disaggregation is that the aggregated values from the tree models after adjustment matched the stand basal area and survival predictions from the standlevel models, resulting in a numerically consistent system.

Tree survival probability was adjusted as follows (eqn. 12):

$$
\widetilde{P}_{i j, t+p}=P_{i j, t+p}^{\lambda}
$$

where $\tilde{P}_{i, t+p}$ and $P_{i, j t+p}$ are, respectively, adjusted and predicted tree survival probability of tree $j$ nested in plot $i$ at the end of the growth interval $t+p, \lambda$ is the adjusting parameter, which is iteratively solved through (eqn. 13):

$\sum_{j} \widetilde{P}_{i j, t+p}=s \hat{N}_{i j, t+p}$ with $N_{\mathrm{i}, t+\mathrm{p}}$ being the stand survival predicted from the stand survival model, and $s$ is the plot size in hectares. Adjustments for future tree diameters were done as follows (eqn. 14):

$$
\widetilde{d}_{i j, t+p}^{2}=d_{i j, t}^{2}+\gamma\left(\hat{d}_{i j, t+p}^{2}-d_{i j, t}^{2}\right)
$$

where ${d_{i, t+p}}_{\text {and }}{\boldsymbol{t}_{\mathrm{i}, t+\mathrm{p}}}_{\text {are, }}$ respectively, adjusted and predicted diameter of tree $j$ in plot $i$ at year $t+p, d_{i, t, t}$ is the observed diameter of $j^{\text {th }}$ tree nested in plot $i$ at year $t$, and (eqn. 15):

$$
\gamma=\frac{s \widetilde{B}_{i, t+p} / K-\sum_{j}\left(\widetilde{P}_{i j, t+p} d_{i j t}^{2}\right)}{\sum_{j} \widetilde{P}_{i j, t+p}\left(\widetilde{d}_{i j, t+p}^{2}-d_{i j, t}^{2}\right)}
$$

and $\tilde{B}_{i, t+p}$ is the stand basal area obtained from eqn. 6.

\section{Model evaluation}

Here, a three-fold cross-validation approach was applied for validating the growth and survival models at both stand and tree levels. Parameter estimates from two replications (fit data) were used to predict the growth and survival of the remaining replication (validation data). Then the procedure was repeated for all the subsets and the final validation data consisted of all replications. Three evaluation statistics, namely mean error (ME), mean absolute error (MAE) and fit index $\left(R^{2}\right)$ were calculated for stand basal area and survival prediction as well as tree diameter prediction (eqn. 16-18):

$$
\begin{aligned}
& M E=\sum_{i}\left(y_{i}-\hat{y}_{i}\right) / n \\
& M A E=\sum_{i}\left|y_{i}-\hat{y}_{i}\right| / n \\
& R^{2}=1-\sum_{i}\left(y_{i}-\hat{y}_{i}\right)^{2} / \sum_{i}\left(y_{i}-\bar{y}_{i}\right)
\end{aligned}
$$

where $y_{i}$ indicates the observed $N, B, Q$, or $d$ of the observation $i, n$ indicates the number of observations, and $\bar{y}$ and $\hat{y}$ are average and predicted values of $N, B, Q$, and $d$,

Tab. 3 - Parameter estimates ( \pm standard errors) of the stand- and tree-level growth and survival models by group. All parameters were significant at the 0.05 level. (Group 1): not containing replication 1; (Group 2): not containing replication 2; (Group 3): not containing replication 3 .

\begin{tabular}{lcccr}
\hline Models & Parameter & Group 1 & Group 2 & \multicolumn{1}{c}{ Group 3 } \\
\hline $\begin{array}{l}\text { Stand-level } \\
\text { models }\end{array}$ & $\alpha_{1}$ & $5.8134 \pm 0.6049$ & $5.5446 \pm 0.5935$ & $5.5420 \pm 0.5735$ \\
& $\alpha_{2}$ & $-0.4423 \pm 0.0686$ & $-0.4052 \pm 0.0672$ & $-0.4158 \pm 0.0653$ \\
& $\alpha_{3}$ & $-1.9376 \pm 0.2896$ & $-2.7626 \pm 0.4705$ & $-1.8974 \pm 0.2831$ \\
& $\chi_{0}$ & $5.1654 \pm 0.9406$ & $5.1133 \pm 0.8885$ & $6.8275 \pm 0.8285$ \\
& $\chi_{1}$ & $0.0654 \pm 0.0102$ & $0.0539 \pm 0.0096$ & $0.0618 \pm 0.0091$ \\
& $\chi_{2}$ & $0.0469 \pm 0.014$ & $0.0664 \pm 0.0156$ & $0.0843 \pm 0.0153$ \\
& $\chi_{3}$ & $-0.0809 \pm 0.0303$ & $-0.0939 \pm 0.0311$ & $-0.1506 \pm 0.0315$ \\
\hline Tree-level & $\chi_{4}$ & $-0.3693 \pm 0.0929$ & $-0.3701 \pm 0.0855$ & $-0.5384 \pm 0.0816$ \\
models & $\delta_{1}$ & $-0.5005 \pm 0.0068$ & $-0.5028 \pm 0.0071$ & $-0.4742 \pm 0.0068$ \\
& $\delta_{2}$ & $0.9963 \pm 0.0309$ & $1.2017 \pm 0.0434$ & $0.9410 \pm 0.0337$ \\
& $\delta_{3}$ & $0.9138 \pm 0.0123$ & $0.8329 \pm 0.0145$ & $0.9341 \pm 0.0144$ \\
\hline
\end{tabular}

respectively.

For tree survival prediction, three evaluation statistics were used, namely ME (mean error), MAE (mean absolute error) and AUC (eqn. 19-20):

$M E=\sum_{i} \sum_{j}\left(y_{i j}-P_{i j}\right) / \sum_{i} n_{1 i}$

$M A E=\sum_{i} \sum_{j}\left|y_{i j}-P_{i j}\right| / \sum_{i} n_{1}$

where $y_{i j}=1$ if the $j$-th tree nested in $i$-th plot survived at the end of the growth interval, and $y_{i j}=0$ otherwise; $P_{i j}$ is the predicted tree survival probability; $n_{1 \mathrm{i}}$ is number of trees ha-1 in $i^{\text {th }}$ plot at the start of the growth interval. AUC is the area under the receiver operating characteristic curve (AUC) commonly applied for evaluating tree mortality model (DeSiervo et al. 2018). It ranged from 0.5 to 1 . The model with larger AUC indicates the tree mortality model performed better.

\section{Results and discussions}

\section{Integrated system of tree- and stand-} level models

Tab. 3 showed the parameter estimates of the growth and survival models in both stand and tree levels, which showed that all parameters of these models were significant at $\alpha=0.05$. Outputs from the stand-level models yielded consistently higher values of $\mathrm{R}^{2}$ and smaller values of MAE as compared to aggregated outputs from the unadjusted tree-level models (Tab. 4). Direct prediction of stand variables apparently was preferable to aggregating tree-level outputs. This result is consistent with the findings by Qin \& Cao (2006) who predicted stand basal area, survival, and volume of loblolly pine (Pinus taeda Linn.), Zhang et al. (2010) who predicted stand basal area and survival of Chinese pine (Pinus tabuliformis Carr.) in China, and Hevia et al. (2015) who predicted stand survival and basal area of birch-dominated stands in Spain. García (2001) reported that problems of accumulation of errors tend to be more serious when aggregating tree-level outputs.

A logical step would be to adjust the treelevel outputs to match the aggregated values with outputs from stand-level models. For many years, the disaggregation method has been used to link tree- and standlevel models. It not only ensured compatibility regarding stand-level outputs, but also yielded better tree-level predictions than the unadjusted approach in former studies (Hevia et al. 2015). Qin \& Cao (2006) found that the success of the disaggregated tree-level predictions depends largely on the precision of the stand-level model.

Tab. 5 shows that the tree-level diameter and survival models derived from the stand growth and survival models performed well. The disaggregated method for tree diameter produced a larger value of $R^{2}$ (0.9468 vs. 0.9434) and a lower value of 
MAE ( 0.5528 vs. 0.6017 ) than did the unadjusted method. This result was supported by Qin \& Cao (2006) for tree diameter prediction and Hevia et al. (2015) for tree basal area prediction. Conversely, the disaggregation method for tree survival yielded lower AUC value (0.8736 vs. 0.8907) and larger MAE value (0.0791 vs. 0.0745) as compared to the unadjusted method (Tab. $5)$. The result of tree survival prediction was contrary to findings from previous studies, which reported superior performance of the disaggregation method (Zhang et al. 2011). The different findings may be due to the ecological differences among the studied species. However, the above results show similar overall performances between the adjusted and unadjusted tree models in terms of predicting tree attributes. The advantage of disaggregation in this study lies in achieving numerical consistency between tree- and standlevel models in predicting stand attributes.

Daniels \& Burkhart (1988) put forward the concept of an integrated system of unified mathematical structure, which can predict forest growth at any level of resolution. The system developed in this study can consistently predict growth and survival at both tree and stand levels. In addition, because the stand models were based on the climate-sensitive self-thinning rule, the tree-level diameter and survival models derived from these stand models should provide reasonable predictions under climate change.

\section{Model predictions under the self- thinning rule}

Fig. 3 displays the change of tree survival probability over time for various diameter percentiles. This figure is based on the plot located in the Fujian province. In this plot, a tree at each $5 \%$ diameter percentile at age 5 was grown to age 30. The graph shows that stand survival rate is equal to tree survival probability at approximately the $20 \%$ diameter percentile. A similar graph was drawn for tree survival basal area in Fig. 4. Change in stand basal area over time is therefore a result of two opposing trends: quadratic mean diameter always increases with time, whereas number of trees is unchanged at first, then begins to decrease with time, and finally follows the self-thinning line. Stand basal area, which is a function of the product of $N$ and $Q^{2}$, increases with time, then stabilizes, and finally decreases (Fig. 4). Surviving tree basal area (computed as survival probability $\times$ tree basal area) behaves differently for different diameter sizes; it increases with time for large diameters, or increases, stabilizes, then decreases with time for small diameters.

Self-thinning usually occurs when the competition for resources (light, nutrient, water, etc.) leads to tree death. Many researchers have used the logistic equation to model tree mortality (Eid \& Tuhus 2001, Yang et al. 2003). However, if the data sets
Tab. 4 - Evaluation statistics for prediction of stand variables from stand-level models and tree-level models (before adjustment). Numbers in italic denote the best statistics for that variable.

\begin{tabular}{llccc}
\hline Variable & $\begin{array}{l}\text { Type of } \\
\text { model }\end{array}$ & $\begin{array}{c}\text { Mean error } \\
(\mathrm{ME})\end{array}$ & $\begin{array}{c}\text { Mean absolute } \\
\text { error }(\mathrm{MAE})\end{array}$ & $\begin{array}{c}\text { Fit index } \\
\left(\mathbf{R}^{2}\right)\end{array}$ \\
\hline $\mathrm{N}: \begin{array}{l}\text { Number of trees } \\
\text { ha }^{-1}\end{array}$ & Stand-level & 3.5358 & 181.646 & 0.9836 \\
\cline { 2 - 5 } $\begin{array}{l}\text { B: Stand basal area } \\
\left(\mathrm{m}^{2} \text { ha-1 }\right)\end{array}$ & Tree-level & -56.1225 & 206.089 & 0.9762 \\
\cline { 2 - 5 } $\begin{array}{l}\text { Q: Quadratic mean } \\
\text { diameter }(\mathrm{cm})\end{array}$ & Tree-level & 1.7019 & 3.7775 & 0.8915 \\
\cline { 2 - 5 } & Stand-level & 0.5531 & 4.3241 & 0.8171 \\
\hline
\end{tabular}

Tab. 5 - Model evaluation statistics of tree diameter growth and survival probabilities models using the three-fold cross-validation by method.

\begin{tabular}{lllllll}
\hline Method & \multicolumn{2}{l}{ Tree diameter } & \multicolumn{4}{l}{ Tree survival probability } \\
\cline { 2 - 7 } & $\mathrm{ME}$ & $\mathrm{MAE}$ & $\mathrm{R}^{2}$ & $\mathrm{ME}$ & $\mathrm{MAE}$ & $\mathrm{AUC}$ \\
\hline Unadjusted & 0.1521 & 0.6017 & 0.9434 & -0.0011 & 0.0745 & 0.8907 \\
\hline Disaggregated & 0.3097 & 0.5528 & 0.9468 & 0.0068 & 0.0791 & 0.8736 \\
\hline
\end{tabular}

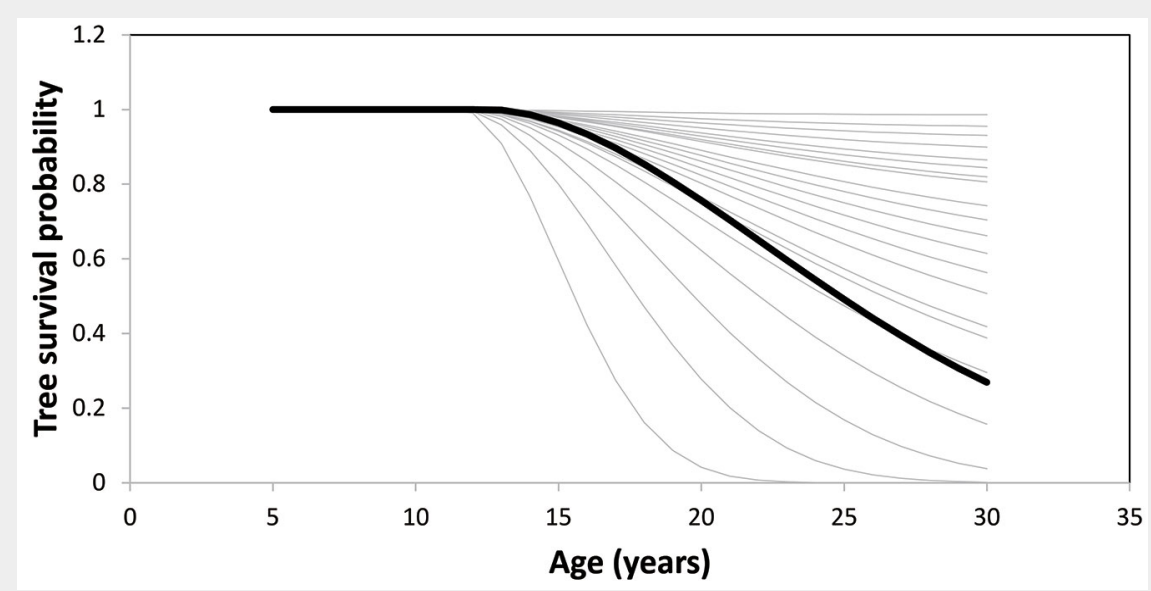

Fig. 3 - Change of tree survival probability over time (thin curve) for various diameter percentiles, from $0 \%$ to $100 \%$, by $5 \%$ intervals for a plot in the Fujian province. The lowest thin curve corresponds to the $0 \%$ diameter percentile, and the top curve corresponds to the $100 \%$ diameter percentile. The dark curve denotes stand survival rate.

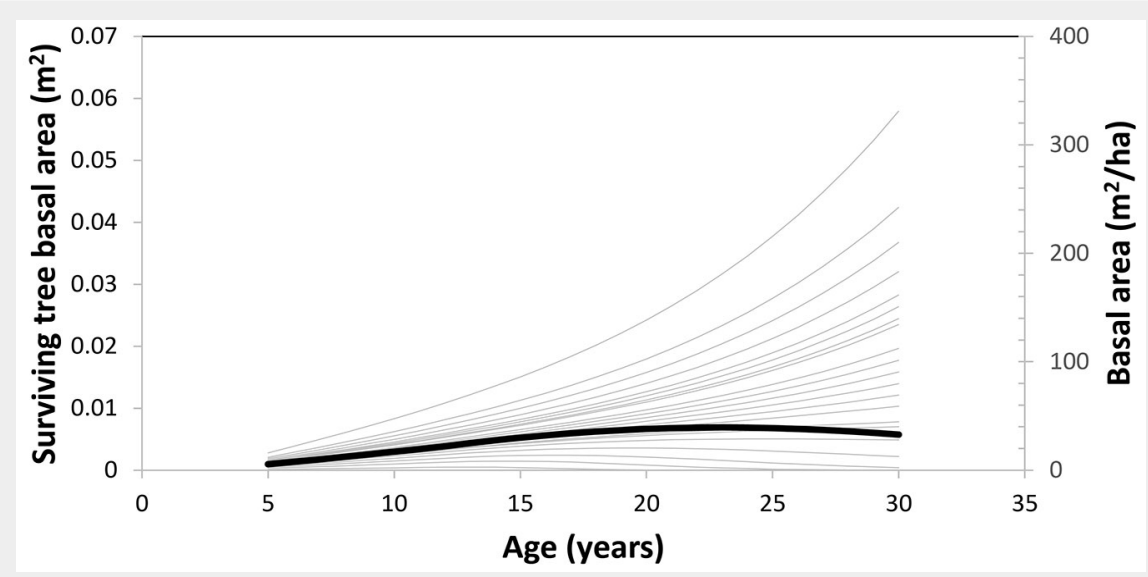

Fig. 4 - Change of tree survival basal area over time (thin curve) for various diameter percentiles, from $0 \%$ to $100 \%$, by $5 \%$ intervals for a plot. The lowest curve corresponds to the $0 \%$ diameter percentile. Tree survival basal area is the product of survival probability and basal area of that tree. The dark curve shows change of stand basal area over time. 
used to develop mortality equations are from short-term remeasurement data, mortality probabilities predicted without considering the self-thinning rule might be compromised by other factors such as drought, frost, snow, etc., which can lead to an increase in prediction errors. Small changes of tree mortality can profoundly influence forest structure (Wyckoff \& Clark 2002). Therefore, underestimation of mortality probabilities would cause unreasonably high estimates of forest growth and yield and vice versa. Hann \& Wang (1990) combined the tree mortality equation with the maximum density function of Douglasfir (Pseudotsuga menziesii (Mirb.) Franco) stands with the objective to produce reasonable tree mortality predictions. Berger et al. (2002) developed the "Kiwi" model that incorporated the self-thinning rule in studying mangrove forest dynamics, and argued that different self-thinning trajectories must be expected because of competition strength of different tree species. In simulating tree-specific mortality, Monserud et al. (2004) found that self-thinning controlled mortality and provided feasible model predictions. Tang et al. (1994) combined the self-thinning and basal area increment models to predict stand density and average diameter, and concluded that the models can be applied to predict stand growth outside the range of the data. Good results were obtained by Ogawa et al. (2010) and Ogawa (2018) for leaf biomass models of hinoki cypress (Chamaecyparis obtusa [Sieb. et Zucc.] Endl.), and Zhang et al. (2020) for stand basal area, quadratic mean diameter, and survival of Chinese fir. In the study by Zhang et al. (2020), stand basal area increased with time, then stabilized, and finally decreased. This confirmed that productivity loss is balanced by gross productivity during the selfthinning process (Berger et al. 2004). The above literature confirms the benefit of incorporating underlying biological principles such as self-thinning into the development of growth and yield models. Because the system of stand models and their derived tree models in this study was based on the self-thinning rule, it is expected to provide reasonable projections outside the range of the data.

\section{Conclusions}

In this study, we developed an integrated system of tree- and stand-level models by deriving tree diameter and survival models from stand growth and survival models. Predictions were reasonable at both stand and tree levels. In addition, the disaggregation approach was applied to provide numerical consistency between models of different resolutions. Compared to the unadjusted approach, predictions from the disaggregation approach were slightly worse for tree survival but slightly better for tree diameter. The advantage of disaggregation in this study lies in achieving numerical consistency between tree- and stand-level models in predicting stand attributes. The stand-level models, based on the self-thinning rule, were compatible with the underlying biological principles. Because they also included climate variables, these stand models and their derived tree-level models formed an integrated system that could offer reasonable predictions for scenarios beyond the data range. Future applications, including those which simulate various climate scenarios, that take advantage of this integrated system could play an important role in managing Chinese fir plantations under climate change.

\section{Acknowledgements}

$\mathrm{XQ}$ analyzed, conceived, and wrote the draft; QV analyzed, reviewed, and improved the draft; YC analyzed the data; JG conceived the study.

\section{Funding}

The study was supported by the National Key Research and Development Program of China (2021YFD2201304) and the National Natural Science Foundation of China (no. 31971645). Partial support for data analysis was received from the National Institute of Food and Agriculture, U.S. Department of Agriculture, Mclntire-Stennis project LAB94379. The authors thank Dr. Aiguo Duan for the field work.

\section{References}

Allen MGII, Coble DW, Cao QV, Yeiser J, Hung I (2011). A modified stand table projection growth model for unmanaged loblolly and slash pine plantations in east Texas. Southern Journal of Applied Forestry 35: 115-122. - doi: 10.1093/sjaf/35.3.115

Bailey RL, Clutter JL (1974). Base-age invariant polymorphic site curves. Forest Science 20: 155159. [online] URL: http://academic.oup.com/for estscience/article-abstract/20/2/155/4675554

Berger U, Hildenbrandt H, Grimm V (2002). Towards a standard for the individual-based modeling of plant populations: self-thinning and the field-of-neighborhood approach. Natural Resource Modelling 15: 39-54. - doi: 10.1111/j.19397445.2002.tboo079.x

Berger U, Hildenbrandt H, Grimm V (2004). Agerelated decline in forest production: modelling the effects of growth limitation, neighbourhood competition and self-thinning. Journal of Ecology 92 (5): 846-853. - doi: 10.1111/j.0022-047 7.2004.00911.x

Bi $\mathrm{H}$ (2001). The self-thinning surface. Forest Science 47: 361-370. [online] URL: http://academ ic.oup.com/forestscience/article/47/3/361/46171 77

Bi H (2004). Stochastic frontier analysis of a classic self-thinning experiment. Austral Ecology 29: 408-417. - doi: 10.1111/j.1442-9993.2004.0137 $9 . x$

Burkhart HE (2013). Comparison of maximum size-density relationships based on alternate stand attributes for predicting tree numbers and stand growth. Forest Ecology and Management 289: 404-408. - doi: 10.1016/j.foreco.20 12.10.041
Burkhart HE, Tomé M (2012). Modeling forest trees and stands. Springer Science and Business Media, Dordrecht, The Netherlands, pp. 458. [online] URL: http://books.google.com/ books?id=XmcNcfEarsoC

Cao QV (2017). An integrated system for modeling tree and stand survival. Canadian Journal of Forest Research 47: 1405-1409. - doi: 10.1139/cj fr-2017-0229

Cao QV (2019). A method to derive a tree survival model from any existing stand survival model. Canadian Journal of Forest Research 49: 1598-1603. - doi: 10.1139/cjfr-2019-0171

Carretero AC, Alvarez ET (2013). Modelling diameter distributions of Quercus suber L. stands in “Los Alcornocales" Natural Park (Cádiz-Málaga, Spain) by using the two-parameter Weibull functions. Forest Systems 22: 15-24. - doi: 10.5424/fs/2013221-02142

Charru M, Seynave I, Morneau F, Rivoire M, Bontemps JD (2012). Significant differences and curvilinearity in the self-thinning relationships of 11 temperate tree species assessed from forest inventory data. Annals of Forest Science 69 (2): 195-205. - doi: 10.1007/s13595-011-0149-0

Daniels RF, Burkhart HE (1988). An integrated system of forest stand models. Forest Ecology and Management 23 (2): 159-177. - doi: 10.1016/ 0378-1127(88)90080-1

DeSiervo MH, Jules ES, Bost DS, De Stigter EL, Butz RJ (2018). Patterns and drivers of recent tree mortality in diverse conifer forests of the Klamath Mountains, California. Forest Science 64 (4): 371-382. - doi: 10.1093/forsci/fxxo22

Eid T, Tuhus E (2001). Models for individual tree mortality in Norway. Forest Ecology and Management 154: 69-84. - doi: 10.1016/S0378-1127 (00)00634-4

García O (2001). On bridging the gap between tree-level and stand-level models. In: Proceedings of IUFRO 4.11 Conference "Forest Biometry, Modelling and Information Science" (Renols K ed). University of Greenwich, London, UK, pp. 311-323.

Ge F, Zeng W, Ma W, Meng J (2017). Does the slope of the self-thinning line remain a constant value across different site qualities? An implication for plantation density management. Forests 8 (10): 355. - doi: 10.3390/f8100355

Hann DW, Wang CH (1990). Mortality equations for individual trees in the mixed-conifer zone of southwest Oregon. Bulletin no. 76, Forest Research Laboratory, Oregon State University, Corvallis, OR, USA, pp. 17. [online] URL: http:// ir.library.oregonstate.edu/concern/technical_re ports/kk91fm84t

Hevia A, Cao QV, Alvarez-González JG, RuizGonzález AD, Von Gadow K (2015). Compatibility of whole-stand and individual-tree models using composite estimators and disaggregation. Forest Ecology and Management 348: 4656. - doi: 10.1016/j.foreco.2015.03.035

Huuskonen S, Miina J (2007). Stand-level growth models for young scots pine stands in Finland. Forest Ecology and Management 241: 49-61. doi: 10.1016/j.foreco.2006.12.024

Lam TY, Guan BT (2020). Modeling stand basal area growth of Cryptomeria japonica D. Don under different planting densities in Taiwan. Journal of Forest Research 25: 174-182. - doi: 10.108 o/13416979.2020.1733171 
Lei JF (2005). Forest resources in China. China Forestry Publish House. Beijing, China, pp. 172. [in Chinese]

Mabvurira D, Miina J (2002). Individual-tree growth and mortality models for Eucalyptus grandis (Hill) Maiden plantations in Zimbabwe. Forest Ecology and Management 161: 231-245. doi: 10.1016/S0378-1127(01)00494-7

Monserud RA, Sterba H (1999). Modeling individual tree mortality for Austrian forest 465 species. Forest Ecology and Management 113: 109-123. - doi: 10.1016/S0378-1127(98)00419-8

Monserud RA, Ledermann T, Sterba H (2004). Are self-thinning constraints needed in a treespecific mortality model? Forest Science 50 (6) 848-858. [online] URL: http://academic.oup. com/forestscience/article/50/6/848/4617278

Nepal SK, Somers GL (1992). A generalized approach to stand table projection. Forest Science 38: 120-133. [online] URL: http://academic. oup.com/forestscience/article-abstract/38/1/120 14642779

Ogawa K (2018). Mathematical consideration of the age-related decline in leaf biomass in forest stands under the self-thinning law. Ecological Modelling 372: 64-69. - doi: 10.1016/j.ecolmodel. 2018.01.015

Ogawa K, Adu-Bredu S, Yokota T, Hagihara A (2010). Leaf biomass changes with stand development of Hinoki cypress (Chamaecyparis obtusa [Sieb. et Zucc.] Endl.). Plant Ecology 211: 79-88. - doi: 10.1007/s11258-010-9774-1

Puettmann KJ, Hann DW, Hibbs DE (1993). Evaluation of the size-density relationships for pure red alder and Douglas-fir stands. Forest Science 39: 7-27. [online] URL: http://academic.oup. com/forestscience/article-abstract/39/1/7/462711 7

Qin J, Cao QV (2006). Using disaggregation to link individual-tree and whole-stand growth models. Canadian Journal of Forest Research
36: 953-960. - doi: 10.1139/x05-284

Reineke LH (1933). Perfecting a stand-density index for even-age forests. Journal of Agricultural Research 46: 627-638.

Ritchie MW, Hann DW (1997). Implications of disaggregation in forest growth and yield modeling. Forest Science 43 (2): 223-233. [online] URL: http://academic.oup.com/forestscience/ article/43/2/223/4627360

SAS Institute (2011). SAS/STAT 9.3 user's guide. SAS Institute, Cary, NC, USA, pp. 3316.

Scolforo HF, Mctague JP, Burkhart H, Roise J, Alvares CA, Stape JL (2019). Modeling wholestand survival in clonal eucalypt stands in Brazil as a function of water availability. Forest Ecology and Management 432: 1002-1012. - doi: 10.1016/j.foreco.2018.10.044

Stankova TV, Diéguez-Aranda U (2020). Dynamic structural stand density management diagrams for even-aged natural stands and plantations. Forest Ecology and Management 458 (2): 117733. - doi: 10.1016/j.foreco.2019.117733

Subedi N, Sharma M (2011). Individual-tree diameter growth models for black jack pine plantations in northern Ontario. Forest Ecology and Management 261: 2140-2148. - doi: 10.1016/j.for eco.2011.03.010

Tang S, Meng CH, Meng FR, Wang YH (1994). A growth and self-thinning model for pure evenage stands: Theory and applications. Forest Ecology and Management 70: 67-73. - doi: 10.1016/0378-1127(94)90075-2

VanderSchaaf CL, Burkhart HE (2012). Development of planting density-specific density management diagrams for loblolly pine. Southern Journal of Applied Forestry 36: 126-129. - doi: 10.5849/sjaf.10-043

Woodall CW, Miles PD, Vissage JS (2005). Determining maximum stand density index in mixed species stands for strategic-scale stocking assessments. Forest Ecology and Management
216: 367-377. - doi: 10.1016/j.foreco.2005.05.050 Wyckoff PH, Clark JS (2002). The relationship between growth and mortality for seven co-occurring tree species in the southern Appalachian Mountains. Journal of Ecology 90: 604615. - doi: 10.1046/j.1365-2745.2002.00691.x Yang Y, Titus SJ, Huang S (2003). Modeling individual tree mortality for white spruce in $\mathrm{Al}$ berta. Ecological Modelling 163 (3): 209-222. doi: 10.1016/S0304-3800(03)00008-5

Yoda K (1963). Self-thinning in overcrowded pure stands under cultivated and natural conditions (intraspecific competition among higher plants XI). Journal of Biology, Osaka City University 14: 107-129.

Zhang X, Lei Y, Cao QV (2010). Compatibility of stand basal area predictions based on forecast combination. Forest Science 56 (6): 552-557. [online] URL: http://academic.oup.com/forest science/article/56/6/552/4604480

Zhang X, Lei Y, Cao QV, Chen X, Liu X (2011). Improving tree survival prediction with forecast combination and disaggregation. Canadian Journal of Forest Research 41: 1928-1935. - doi: 10.1139/x11-109

Zhang X, Cao QV, Duan A, Zhang J (2016). Selfthinning trajectories of Chinese fir plantations in Southern China. Forest Science 62 (6): 594599. - doi: 10.5849/forsci.16-004

Zhang X, Lu L, Cao QV, Duan A, Zhang J (2018). Climate-sensitive self-thinning trajectories of Chinese fir plantations in south China. Canadian Journal of Forest Research 48 (11): 1388-1397. doi: 10.1139/cjfr-2018-0168

Zhang X, Cao QV, Wang H, Duan A, Zhang J (2020). Projecting stand survival and basal area based on a self-thinning model for Chinese fir plantations. Forest Science 66: 361-370. - doi: 10.1093/forsci/fxzo86 